\title{
In vitro Release and in vivo Anti-tumor Efficacy of Doxorubicin from Biodegradable Temperature-sensitive Star-shaped PLGA-PEG Block Copolymer Hydrogel
}

\author{
By Su Jeong LEE, ${ }^{1}$ Yoonsoo BAE, ${ }^{2}$ Kazunori KATAOKA, ${ }^{2}$ \\ Dukjoon KIM, ${ }^{3}$ Doo Sung LEE, ${ }^{4}$ and Sung Chul KIM ${ }^{1, *}$
}

\begin{abstract}
Doxorubicin (DXR) was loaded into two kinds of thermo-responsive biodegradable star-shaped block copolymer (4arm PLGA-PEG) solutions with different PLGA block lengths under various conditions (drug-concentrations, polymerconcentrations and block compositions). All release profiles of DXR from star-block copolymer hydrogels showed sustained patterns. To assess this polymer as a sustained drug-delivery formulation, in vivo anti-tumor efficacy was examined by using tumor-bearing mice treated with DXR-loaded/ DXR-free hydrogels based on the result of the release study. After 1 month, the mice treated with DXR-loaded S11-C1 and DXR-loaded S9-C1 copolymer solutions had remarkably suppressed tumorvolume compared to that of the mice treated with DXR-free copolymer solution. And DXR-loaded S11 hydrogel showed more significant tumor inhibition due to the different hydrophobicity between S9 and S11 copolymers. In vitro release and in vivo anti-tumor activity studies performed for 1 month revealed the potential of this hydrogel as a sustained and long-term drug delivery carrier.

KEY WORDS: Biopolymers / Degradable / Hydrogel / Temperature-sensitive / Anti-tumor Efficacy /
\end{abstract}

Temperature-sensitive polymer hydrogels which exhibit a sol-gel phase transition behavior in an aqueous solution with increasing the temperature have been attracted as carriers for the injectable drug delivery systems. As an example, Pluronics or Poloxamers, triblock copolymers composed of poly(ethylene oxide-b-propylene oxide-b-ethylene oxide), flow at room temperature, but form gels at body temperature at a specific concentration. So, Poloxamers might be mixed with therapeutic agents such as drugs, cells or proteins in a sol state and injected using a syringe into the body to form an in situ gel-forming drug depot. There are a large number of reports on Poloxamer hydrogels used for the sustained delivery of several drugs such as melanotan-I (MT-I), mitomycin C, interleukin-2, and urease. ${ }^{1-5}$ Most release profiles show sustained release kinetics over several hours (4-8 h). Use of Poloxamer hydrogel provides the drug-stability and sustained release formulation. However, Poloxamers have several drawbacks, such as a non-degradability, dissolution at the injection site in a few days and toxicity.

Recently, hydrogel-based injectable polymers possessing themogelation, biodegradablility, and non-toxicity have been developed for the long-term delivery system of a variety of drugs. Among them, PEG-PLGA-PEG or PLGA-PEG-PLGA block copolymers composed of poly(ethylene glycol) and poly(DL-lactide-co-glycolide) exhibit reversible sol-gel transition behavior. ${ }^{6,7}$ These gels remain at the injection site for approximately 1 month in contrast to Poloxamers. ${ }^{8}$ Several drug release cases from PEG-PLGA-PEG and ReGel (PLGAPEG-PLGA) hydrogel were reported. The more hydrophilic ketoprofen was released slowly over 2 weeks, while the more hydrophobic spironolactone was released over 2 months from PEG-PLGA-PEG hydrogels. ${ }^{9}$ For several drugs including 5fluorouracil, indomethacin, paclitaxel, and various protein pharmaceuticals, release from ReGel showed a sustained release for 1-6 weeks. $^{10,11}$ However, these linear block copolymer systems have a limitation of molecular weight by a triblock topology. They should have only molecular weight of 4000-5000 to show a sol-gel transition below $37^{\circ} \mathrm{C}$. To overcome such a molecular weight limitation, gelation behavior of graft copolymer systems (PLGA-g-PEG) was studied. ${ }^{12}$ From this point of view, the study on star-block copolymer systems showing sol-gel transition behavior is worth, because they can have a wide range of molecular weight from the multiinitiator and form well-defined structures.

Doxorubicin (DXR, trade name Adriamycin) is an anticancer drug widely used in chemotherapy. It exerts its cytotoxic activity by inhibiting DNA and RNA biosynthesis within cancer cells. ${ }^{13-15}$ But, to overcome several problems such as its cytotoxicity to normal tissue and inherent multi-drug resistance effect and to improve the therapeutic effects, several drug delivery systems including polymer-drug conjugates, liposomes, nanoparticles, and polymeric micelles have been developed. ${ }^{16-18}$

\footnotetext{
${ }^{1}$ Department of Chemical and Biomolecular Engineering, Korea Advanced Institute of Science and Technology, 373-1, Guseong-dong, Yuseong-gu, Daejon 305-701, Korea

${ }^{2}$ Department of Materials Science and Engineering, Graduate School of Engineering, The University of Tokyo, 7-3-1 Hongo, Bunkyo-ku, Tokyo 1138656, Japan

${ }^{3}$ Department of Chemical Engineering, Sungkyunkwan University, Suwon 440-746, Korea

${ }^{4}$ Department of Polymer Science and Engineering, Sungkyunkwan University, Suwon 440-746, Korea

*To whom correspondence should be addressed (Tel: +82-42-869-3914, Fax: +82-42-869-8435, E-mail: kimsc@kaist.ac.kr).
} 
Recently, we reported star-shaped 4arm PLGA-PEG block copolymers with different hydrophobic block lengths and different hydrophilic/hydrophobic ratio. ${ }^{19}$ These polymers show temperature-sensitive sol-gel-sol phase transition behavior at specific composition ( $>24 \mathrm{wt} \%$ ). In this study, starshaped block copolymer solution containing doxorubicin was prepared as a sustained drug carrier. With varying the polymer concentrations, doxorubicin contents and polymer compositions, drug release study was investigated in vitro. On the basis of the in vitro release study the anti-tumor activity was also evaluated on human tumor xenografted on nude mice in vivo.

\section{EXPERIMENTAL SECTION}

\section{Materials}

Monomethoxy poly(ethylene glycol) (MPEG, $M_{\mathrm{n}}=550$ ), pentaerythritol, DL-lactide, stannous 2-ethylhexanoate ( $\left.\mathrm{Sn}(\mathrm{oct})_{2}\right)$, 4-(dimethylamino) pyridine (DMAP) and 1,3dicyclohexylcarbodiimide (DCC) were used as received from Sigma-Aldrich. Glycolide was supplied by Purac and succinic anhydride and triethylamine were purchased from Junsei and Acros, respectively. Adriamycin hydrochloride (ADR-HCl) was supplied from Nippon Kayaku, Japan. MPEG was dried in vacuo at $80^{\circ} \mathrm{C}$ for $10 \mathrm{~h}$ before use. All other chemicals were of reagent grade and were used as received without purification.

\section{Animals and Tumor Cell Lines}

Female, 6-week-old, CD1 mice (20-30 g body weight) were purchased from Charles River, Japan. The animals were cared for and all of the animal experiments were performed in accordance with the Guide for the Care and Use of Laboratory Animals as adopted and promulgated by the National Institutes of Health (NIH). KB cells were kindly supplied from the National Cancer Center Research Institute, Japan and cultured in DMEM (Sigma) containing $10 \%$ fetal bovine serum in a humidified atmosphere with $5 \% \mathrm{CO}_{2}$ at $37^{\circ} \mathrm{C}$.

\section{Synthesis of Temperature-sensitive Star-block Copolymer}

Two kinds of temperature-sensitive star-shaped 4arm PLGA-PEG block copolymers with different hydrophobic block lengths were prepared. In the previous work, we described the synthesis of these polymers, characterization, micellization behavior and gelation behavior. ${ }^{19}$

Briefly, star-shaped 4arm PLGA-PEG block copolymers were synthesized from the following procedures: First, by using succinic anhydride, MPEG was carboxylated to produce $\alpha$-monocarboxyl- $\omega$-monomethoxypoly(ethylene glycol) (CMPEG) with carboxylic acid terminal group. Second, hydroxy-terminated star-shaped 4arm PLGA was polymerized from bulk ring-opening polymerization of DL-lactide and glycolide in the presence of multifultional-initiator, pentaerythritol at $150^{\circ} \mathrm{C}$ for $6 \mathrm{~h}$. The molecular weight of 4arm PLGA block was controlled by the feed ratio of lactide and glycolide to pentaerythritol. Finally, we obtained 4arm PLGA-PEG from the coupling reaction of two reactive precursors, 4arm PLGA
Table I. Molecular weights of 4arm PLGAs and 4arm PLGA-PEGs

\begin{tabular}{|c|c|c|c|c|c|c|c|}
\hline \multirow{2}{*}{ Code } & \multirow{2}{*}{ Sample } & \multirow{2}{*}{$M_{\mathrm{n}, \mathrm{th}^{\mathrm{a}}}{ }^{\mathrm{a}}$} & \multirow{2}{*}{$M_{\mathrm{n}, \mathrm{NMR}}$} & \multicolumn{3}{|c|}{ GPC } & \multirow{2}{*}{$\begin{array}{c}\text { PEG } \\
\text { content }^{c} \\
\text { (wt \%) }\end{array}$} \\
\hline & & & & $M_{\mathrm{n}}$ & $M_{\mathrm{w}}$ & $\overline{\mathrm{PDI}^{\mathrm{b})}}$ & \\
\hline S9 & 4arm $\mathrm{P}\left(\mathrm{L}_{75} \mathrm{G}_{25}\right)$ 9-PEG550 & 7672 & 7670 & 8630 & 10700 & 1.24 & 34 \\
\hline S11 & 4arm $\mathrm{P}\left(\mathrm{L}_{75} \mathrm{G}_{25}\right)$ 11-PEG550 & 8769 & 8850 & 10290 & 12560 & 1.22 & 29 \\
\hline
\end{tabular}

and CMPEG. In Table I, molecular weights and molecular weight distributions of synthesized star polymers, S9 and S11, were summarized. The lengths of their hydrophobic block, 4arm PLGA, were different, while lactide/glycolide ratio was fixed at 75:25.

\section{In vitro Biodegradability of Star-block Copolymer Hydro- gels}

The in vitro biodegradability of star-block copolymer hydrogels was evaluated by measuring the changes in molecular weight at $37^{\circ} \mathrm{C}$ in phosphate buffered saline (PBS) (pH 7.4). $0.4 \mathrm{~mL}$ of star-block copolymer hydrogels with initial polymer solutions of $36 \mathrm{wt} \%$ were prepared in a vial, which was kept in incubator with gentle stirring at $37^{\circ} \mathrm{C}$. After $10 \mathrm{~min}, 3.5 \mathrm{~mL}$ of $\mathrm{PBS}\left(\mathrm{pH} 7.4,37^{\circ} \mathrm{C}\right)$ was added into the formed gel. The samples were taken at specific time intervals. The remaining gels were freeze-dried and their molecular weight changes were determined by GPC. In addition, the $\mathrm{pH}$ changes of upper solutions were measured with $\mathrm{pH}$ meter (Istek 735P).

\section{Preparation of DXR-loaded Star-block Copolymer Hydro- gel}

To study the in vitro release behavior of temperaturesensitive star-block copolymers, hydrogels with various polymer concentrations and drug contents were prepared as follows: Desired amount of the star-block copolymer was weighted into $1.5 \mathrm{~mL}$ microcentrifuge tubes. And then, Tris$\mathrm{HCl}$ buffer ( $\mathrm{pH} 7.4, \mathrm{NaCl} 150 \mathrm{mM}$ ) containing DXR in the concentrations ranging from 2 to $0.5 \mathrm{mg} / \mathrm{mL}(2,1,0.5 \mathrm{mg} / \mathrm{mL})$ were added into each tube to produce desired polymer solution (total weight $0.1 \mathrm{~g}$ ). $32 / 34 / 36 \mathrm{wt} \%$ and $36 / 38 / 40 \mathrm{wt} \%$ polymer solutions which become gels at body temperature $\left(37^{\circ} \mathrm{C}\right)$ were prepared for S11 and S9, respectively. The experimental

Table II. Experimental group for anti-tumor of star-block copolymer hydrogel

\begin{tabular}{cccccccc}
\hline Group & $\begin{array}{c}\text { Polymer } \\
\text { conc. } \\
\text { (wt } \%)\end{array}$ & $\begin{array}{c}\text { DXR } \\
\text { conc. } \\
(\mathrm{mg} / \mathrm{mL})\end{array}$ & $\begin{array}{c}\text { DXR } \\
\text { dose } \\
(\mathrm{mg} / \mathrm{kg})\end{array}$ & Group & $\begin{array}{c}\text { Polymer } \\
\text { conc. } \\
\text { (wt \%) }\end{array}$ & $\begin{array}{c}\text { DXR } \\
\text { conc. } \\
(\mathrm{mg} / \mathrm{mL})\end{array}$ & $\begin{array}{c}\text { DXR } \\
\text { dose } \\
(\mathrm{mg} / \mathrm{kg})\end{array}$ \\
\hline S9-C1 & 36 & 2 & $10^{\mathrm{a})}$ & S11-A1 & 32 & 2 & - \\
S9-C2 & 36 & 1 & - & S11-B1 & 34 & 2 & - \\
S9-C3 & 36 & 0.5 & - & S11-C1 & 36 & 2 & $10^{\mathrm{a})}$ \\
S9-D1 & 38 & 2 & - & S11-C2 & 36 & 1 & - \\
S9-E1 & 40 & 2 & - & S11-C3 & 36 & 0.5 & - \\
\hline
\end{tabular}

a) Copolymers used in in vivo anti-tumor activity study *Injection volume: $100 \mu \mathrm{m}$ 


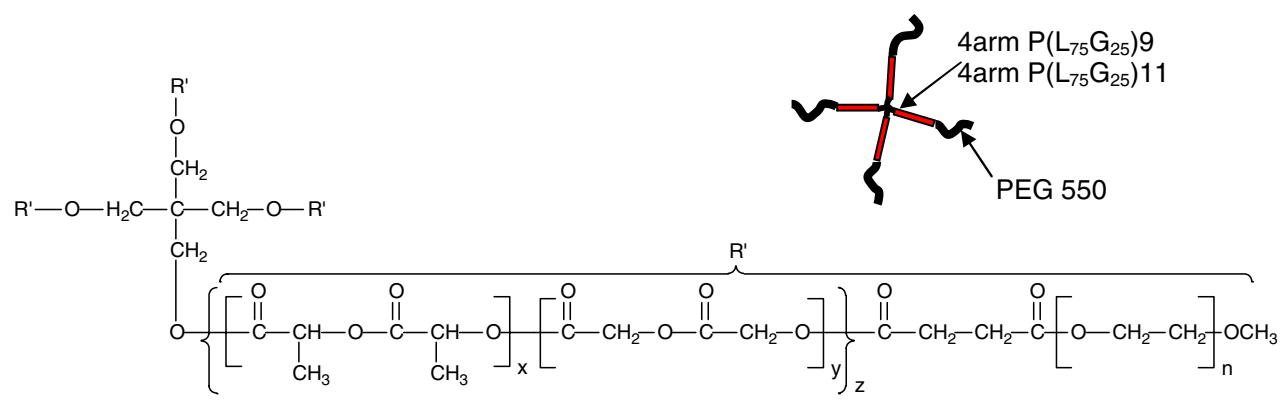

Figure 1. Chemical structure of star-shaped 4arm PLGA-PEG block copolymer.

groups for the in vitro release were summarized in Table II. After 2-3d, polymer and DXR/Tris-HCl buffer formed a homogeneous solution at room temperature. The solution was incubated at $37^{\circ} \mathrm{C}$ for $10 \mathrm{~min}$ to form gel.

In vitro DXR Release from Star-block Copolymer Hydrogel

The release experiment in vitro was carried out as follows: $1 \mathrm{~mL}$ of $100 \mathrm{mM}$ Tris- $\mathrm{HCl}$ buffer $(\mathrm{pH} 7.4, \mathrm{NaCl} 150 \mathrm{mM})$ as a release medium $\left(37^{\circ} \mathrm{C}\right)$ was added into polymer gel prepared previously. And then, tubes were kept in incubator with gentle stirring at $37^{\circ} \mathrm{C}$. At specific time intervals, $5 \mu \mathrm{L}$ of whole release medium was sampled. The amount of released DXR was determined using a spectrofluorometer (Fluoroskan Ascent ${ }^{\circledR}$ FL, Labsystems) with an excitation wavelength of $485 \mathrm{~nm}$ and an emission wavelength of $590 \mathrm{~nm}$ in comparison to the standard curve.

\section{In vivo Anti-tumor Activity of DXR-loaded Star-block Copolymer Hydrogel}

The anti-tumor activity of the drug loaded star-block copolymer hydrogel was evaluated with tumor-bearing, 6week-old, female CD-1 mice ( $n=4$, Charles River, Japan). $\mathrm{KB}$ cells were inoculated subcutaneously into the central on day 0. In vivo experiment was started on $7 \mathrm{~d}$ after tumor implantation when the tumor volume reached about $100 \mathrm{~mm}^{3}$. The temperature-sensitive polymer solution was prepared to 36 wt \% concentration. The DXR-loaded and DXR-free polymer solution was injected subcutaneously into the left flank region of tumor-bearing mouse by using a syringe. The DXR treatment groups (S9, S11) were injected with $100 \mu \mathrm{L}$ of DXR-loaded $(2 \mathrm{mg} / \mathrm{mL})$ polymer solution (equivalent to 10 $\mathrm{mg} / \mathrm{kg}$ of mouse DXR dose) subcutaneously into the left flank region. The control groups, drug-free polymer solutions of S9 and S11 (Control S9-C, Control S11-C), were injected with $100 \mu \mathrm{L}$ of polymer solutions subcutaneously into the left flank region to compare anti-tumor activity of DXR-loaded hydrogel with that of DXR-free hydrogel. The size of tumor mass (the length and the width) was measured with a caliper and tumor volume was calculated by using the following equation: Tumor volume $=1 / 2 \mathrm{LW}^{2}$, where $\mathrm{L}$ and $\mathrm{W}$ denote the length and the width, respectively. The body weight of the mice was measured to evaluate the toxicity of the hydrogel.

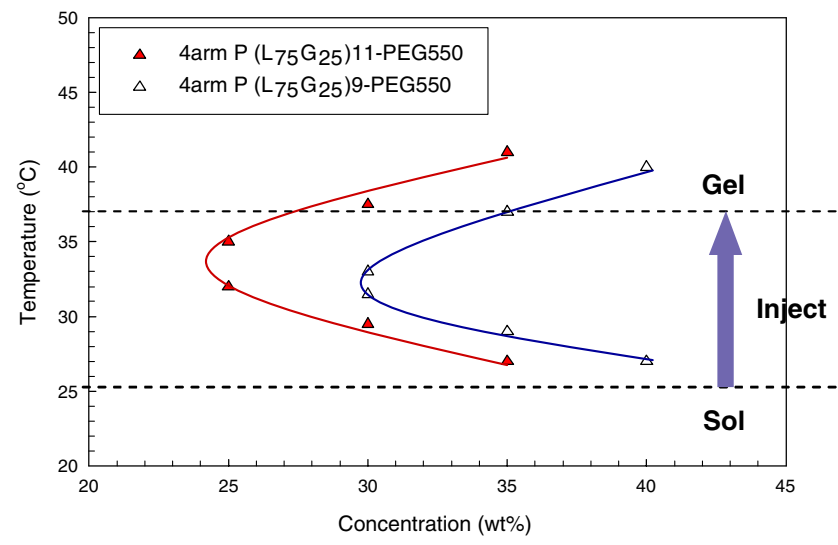

Figure 2. Sol-gel-sol phase diagram of star-block copolymers in an aqueous solution.

\section{RESULTS AND DISCUSSION}

The structures of the 4arm PLGA-PEG block copolymers with different hydrophobic block length are shown in Figure 1. Their average-number of monomeric unit in one arm of $4 \mathrm{arm}$ PLGA was varied by 9 and 11 repeat units at a fixed mole ratio of lactide to glycolide (75:25) and the molecular weight of PEG was fixed at 550. Table I summarizes the molecular weight and molecular weight distribution of the synthesized star block copolymer. As shown in Figure 2, these polymers show the sol to gel and gel to sol transition behavior at specific composition $(>24 \mathrm{wt} \%$ ). They flow in sol state at room temperature, while they form gel at body temperature. The phase diagram of S11 with the more hydrophobic PLGA block shifted left compared to that of S9 due to the enhanced hydrophobicity.

\section{In vitro Degradation of Star-block Copolymer Hydrogels}

It is important to know in vitro degradation profiles before in vitro release and anti-tumor efficacy tests. In vitro degradation of star-block copolymers was studied in PBS (pH 7.4) at $37^{\circ} \mathrm{C}$. Figure 3 shows the molecular weight $\left(M_{\mathrm{n}}\right.$ by GPC) changes of star-block copolymer hydrogels with different hydrophobic block length during degradation time of one month. The molecular weights by GPC decreased slowly from 10290 to 6400 and from 8630 to 4320 in S11-C and S9-C, respectively. S11-C with longer hydrophobic block showed a little slower 


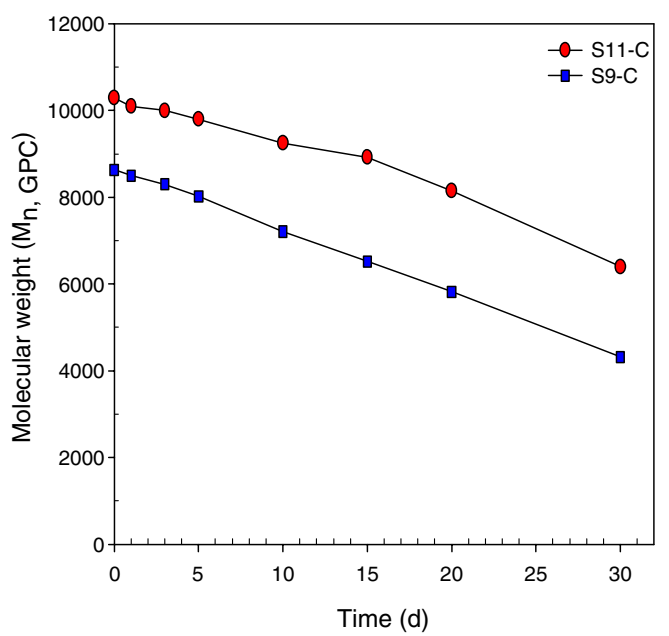

Figure 3. Molecular Weight ( $M_{\mathrm{n}}$ by GPC) changes of star-block copolymers during degradation.

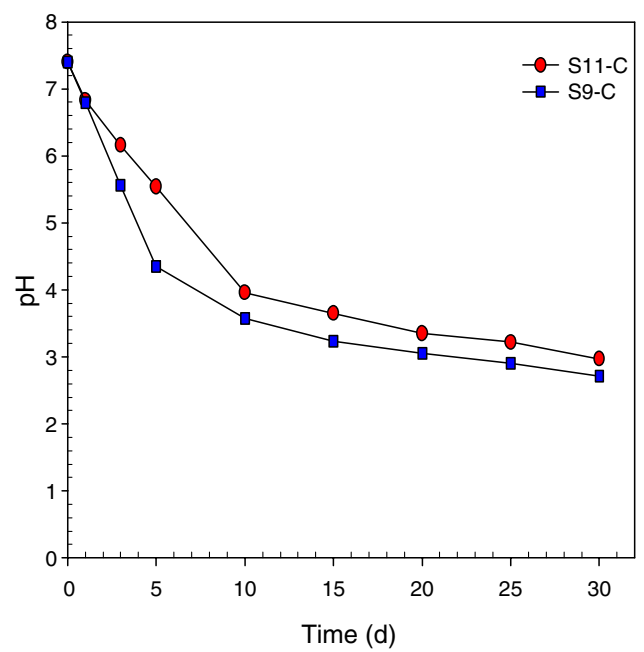

Figure 4. $\mathrm{pH}$ changes of star-block copolymer hydrogels during degradation.

degradation rate than S9-C. This is due to the slower hydrolysis of aliphatic polyester caused by the lower hydration of the gel in S11-C. This tendency was also evidenced by the result of $\mathrm{pH}$ changes during degradation. (Figure 4) The $\mathrm{pH}$ of S11-C and S9-C block copolymer solutions was observed to decrease from 7.4 to around 3 during one month as a result of hydrolytic degradation. However, S11-C showed slower $\mathrm{pH}$ decrease during the first weak due to the longer PLGA block. These different degradation profiles affect in vitro release and in vivo mice studies.

\section{In vitro Release of ADR from Star-block Copolymer Hydrogel}

Hydrogels with different drug-concentrations, polymerconcentrations and block compositions were prepared and in vitro drug release test was performed in Tris-buffer solution $\left(\mathrm{pH} 7.4, \mathrm{NaCl} 150 \mathrm{mM}\right.$ ) at $37^{\circ} \mathrm{C}$ as a preceding test for evaluating the ability of temperature-sensitive star-block copolymer hydrogels to deliver DXR. (a)

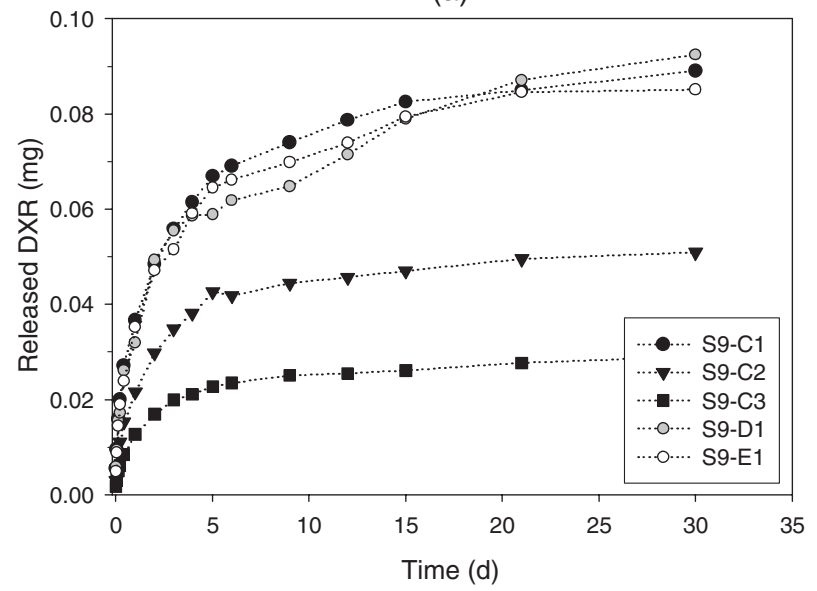

(b)

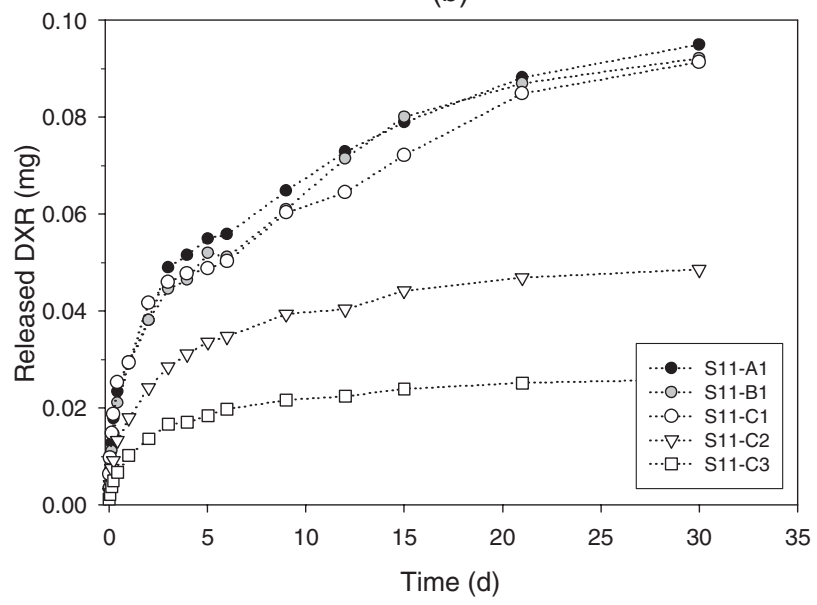

Figure 5. DXR release profile from (a) S9-C, -D, -E (b) S11-A, -B, -C and copolymer hydrogels.

Figure 5 shows the released DXR content $(\mathrm{mg})$ profile from S11- and S9-series hydrogels under various conditions. All DXR release profiles show the moderate release rates. These pseudo zero-order release patterns indicate that these gels have the potential of long-term drug carriers. S9-C1 and S11-C1 hydrogels (36wt \% of polymer solutions with DXR of 2 $\mathrm{mg} / \mathrm{mL}$ ) contained DXR of $0.128 \mathrm{mg}$, of which about $70 \%$ $(0.09 \mathrm{mg})$ was released for one month. S11-C1 hydrogel released $0.049 \mathrm{mg}$ for $5 \mathrm{~d}$, afterwards it showed slower release pattern than S9-C1 due to the different PLGA length. Of course with decreasing contained DXR concentration, the amount of released DXR decreased. These different release profiles for hydrogels containing various amounts of drugs can make it possible to fine-tune the drug release rate.

Figure 6 shows the DXR release profiles based on the percentage. Figure $6 \mathrm{a}$ shows the effect of the drug concentration on the profile of DXR release. As the drug content was increased, the drug release rate decreased. DXR disperses well in the hydrophobic core segment, while a crystallization of drug in the hydrophobic PLGA core occurs in case of high drug content. Figure $6 \mathrm{~b}$ shows the DXR release profiles of hydrogels 
(a)

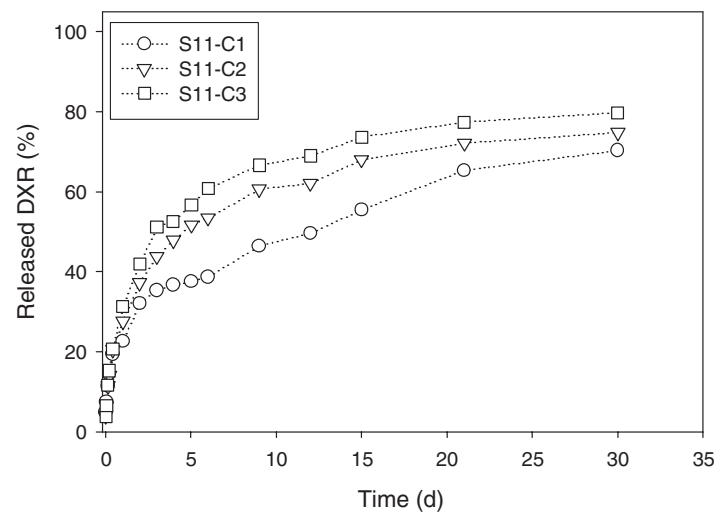

(b)

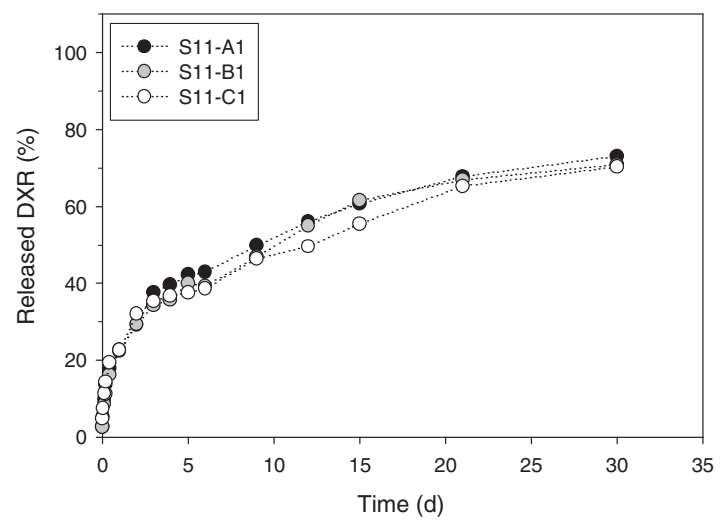

(c)

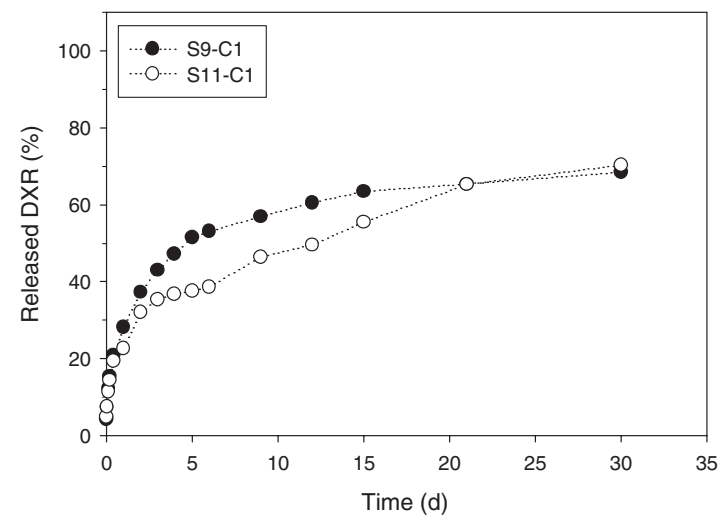

Figure 6. In vitro release profiles of DXR from hydrogels incorporating antitumor drugs (a) Effect of the drug concentration on the profile of DXR release (b) Effect of the polymer concentration on the profile of DXR release (c) Effect of the hydrophobic block length in star-shaped block copolymer on the profile DXR release.

formed from different polymer concentrations. Actually, it was reported that the higher the initial polymer concentration, the slower drug release rate due to the tighter polymer-polymer contacts inside the gel at higher concentrations of the polymer. ${ }^{9}$ But, in this study, the effect of the polymer concentration on the drug release rate is not significant. However, as you can see in Figure 6c, from the DXR release profiles of S9-C1 and S11$\mathrm{C} 1$ with different hydrophobic block lengths at fixed polymer

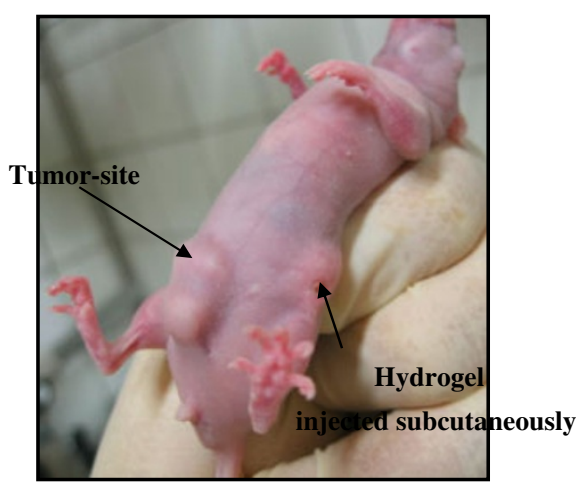

Figure 7. Mice bearing tumor

concentration and drug content, it was found that the larger the molecular weight of the hydrophobic block, the slower the rate of DXR release. It was due to the enhanced hydrophobicity, which make the interactions between polymer and drug stronger and make the hydrolytic degradation slow as discussed above. So, even though two gels had same drug contents, especially, at earlier stage $\mathrm{S} 11$ showed slower drug release rate.

\section{In vivo Anti-tumor Efficacy of DXR-loaded Star-block Copolymer Hydrogel}

Based on the previous in vitro release results, star-block copolymer hydrogels containing same DXR content of $2 \mathrm{mg}$ / $\mathrm{mL}$ and different PLGA molecular weights (S9-C1, S11-C1) were chosen to assess the in vivo anti-tumor activity. CD-1 mice bearing tumors were used. $100 \mu \mathrm{L}$ of DXR-loaded and unloaded star-block copolymer solutions were subcutaneously injected into left flank and the gel was formed within $5 \mathrm{~min}$ as shown in Figure 7.

Figure 8 shows the volume change of tumor mass after application of S9-C1 and S11-C1 incorporating $10 \mathrm{mg} / \mathrm{kg}$ of DXR and drug-free S9-C and drug-free S11-C as a control group for $30 \mathrm{~d}$. There was little difference in tumor-volume change between groups Control S9-C and Control S11-C regardless of the composition of drug-free hydrogels. But, the increase of the tumor-volume of the mice treated with DXRloaded hydrogels (groups S9-C1 and S11-C1) was significantly reduced. In other words, S9-C1 and S11-C1 hydrogels incorporating DXR suppressed the tumor-growth. After 1 month, tumor volume of the mice treated with drug-free copolymer solution was about $5000 \mathrm{~cm}^{3}$, while those of the mice treated with DXR-loaded S11-C1 and DXR-loaded S9-C1 hydrogels were about $1200 \mathrm{~cm}^{3}$ and $2300 \mathrm{~cm}^{3}$, respectively. As mentioned previously, due to the different drug release profiles between S9-C1 and S11-C1 caused by the different hydrophobicity, DXR-loaded S11-C1 hydrogel showed significant tumor inhibition.

Figure 9 shows the body weight change of the tumorbearing mice following application. In case of the groups injected drug-free hydrogel, the body weight of mice continuously increased because of the rapid growth of tumor mass. A dramatic weight loss in mice treated with the hydrogel was not 


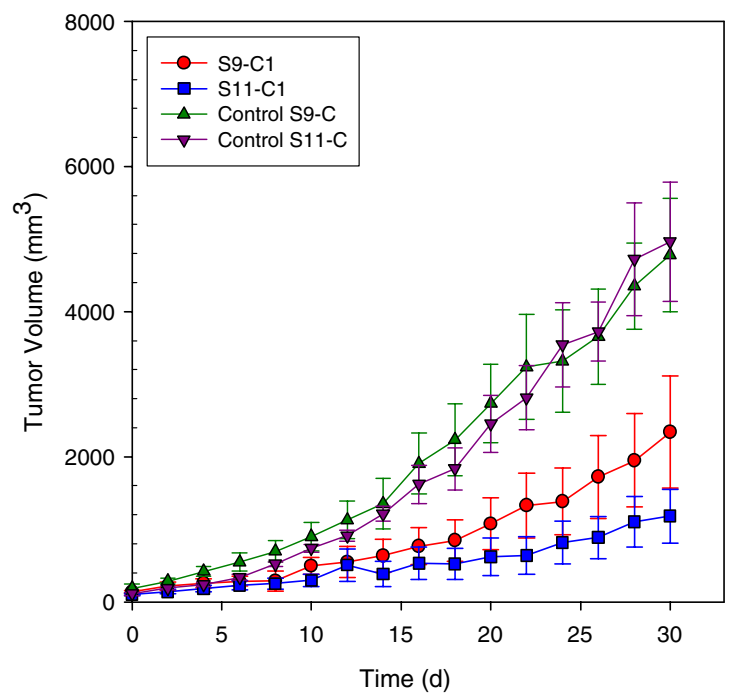

Figure 8. In vivo anti-tumor activity of DXR-loaded star-block copolymers after administration. The values are expressed as means \pm SEM $(n=4)$.

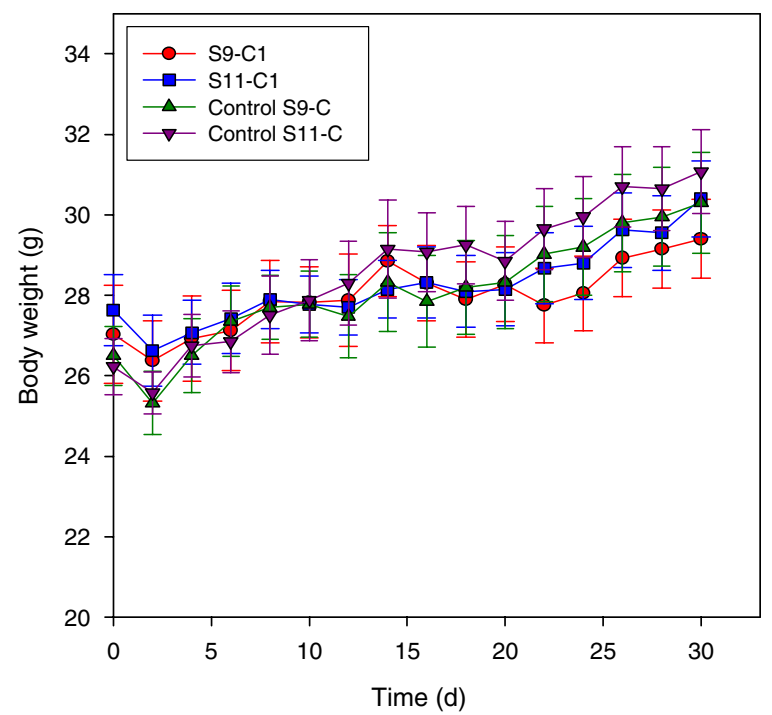

Figure 9. Body weight changes of mice treated DXR-loaded star-block copolymers after administration. The values are expressed as means \pm SEM $(n=4)$.

observed, which indicates no toxicity of DXR that was delivered by the hydrogel.

\section{CONCLUSIONS}

Temperature-sensitive biodegradable star-shaped block copolymer was synthesized by varying the hydrophobic block length. To evaluate this polymer as a sustained drug-delivery formulation, we carried out in vitro drug release and in vivo anti-tumor efficacy study for one month. The anti-tumor activity of star-shaped copolymer hydrogels containing doxo- rubicin was evaluated. All release profiles for DXR-loaded hydrogels showed the sustained release patterns. The more the loaded-drug content and the longer the hydrophobic block length, the slower the drug release rate. Due to these different drug release profiles between $\mathrm{S} 9$ and $\mathrm{S} 11$ caused by the different hydrophobicity, drug-loaded S11-C1 hydrogel showed more significant tumor inhibition. This result reveals the potential of this hydrogel as a sustained and long-term drug delivery carrier.

Received: October 19, 2007 Accepted: November 12, 2007 Published: December 26, 2007

\section{REFERENCES}

1. W. Brown, K. Schillen, M. Almgren, S. Hvidt, and P. Bahadur, J. Phys. Chem., 95, 1850 (1991).

2. R. Bhardwaj and J. Blanchard, J. Pharm. Sci., 85, 915 (1996).

3. S. Miyazaki, Y. Ohkawa, M. Takada, and D. Attwood, Chem. Pharm. Bull., 40, 2224 (1992).

4. T. P. Johnston, M. A. Punjabi, and C. Froelich, J. Pharm. Res., 9, 425 (1992).

5. K. A. Fults and T. P. Johnston, J. Parenter. Sci. Technol., 44, 58 (1990).

6. B. Jeong, Y. H. Bae, D. S. Lee, and S. W. Kim, Nature, 388, 860 (1997).

7. M. S. Shim, H. T. Lee, W. S. Shim, I. Park, H. Lee, T. Chang, S. W. Kim, and D. S. Lee, J. Biomed. Mater. Res., 61, 188 (2002).

8. B. Jeong, Y. H. Bae, and S. W. Kim, J. Biomed. Mater. Res., 50, 171 (2000).

9. B. Jeong, Y. H. Bae, and S. W. Kim, J. Controlled Release, 63, 155 (2000).

10. M. Qiao, D. Chen, X. Ma, and Y. Liu, Int. J. Pharm., 294, 103 (2005).

11. G. M. Zentner, R. Rathi, C. Shih, J. C. McRea, M. H. Seo, H. Oh, B. G. Rhee, J. Mestecky, Z. Moldoveanu, M. Morgan, and S. Weitman, J. Controlled Release, 72, 203 (2001).

12. B. Jeong, L. Q. Wang, and A. Gutowska, Chem. Commun., 16, 1516 (2001).

13. R. H. Blum and S. K. Carter, Ann. Intern. Med., 80, 249 (1974).

14. D. Marco and C. Chemother, Rep. 6, 91 (1975).

15. R. A. Bender, L. A. Zwelling, J. H. Doroshow, G. Y. Locker, K. R. Hande, D. S. Murison, M. Cohen, C. E. Myers, and B. A. Chabner, Drugs, 16, 46 (1978).

16. P. A. Vasey, S. B. Kaye, R. Morrison, C. Twelves, P. Wilson, R. Duncan, A. H. Thomson, L. S. Murray, T. E. Hilditch, T. Murray, S. Burtles, D. Fraier, E. Frigerio, and J. Cassidy, Clin. Cancer Res., 5, 83 (1999).

17. A. N. Gordon, J. T. Fleagle, D. Guthrie, D. E. Parkin, M. E. Gore, and A. J. Lacave, J. Clin. Oncol., 19, 3312 (2001).

18. T. Nakanishi, S. Fukushima, K. Okamoto, M. Suzuki, Y. Matsumura, M. Yokoyama, T. Okano, Y. Sakurai, and K. Kataoka, J. Contr. Rel., 74, 295 (2001).

19. S. J. Lee, B. R. Han, S. Y. Park, D. K. Han, and S. C. Kim, J. Polym. Sci., Part A: Polym. Chem., 44, 888 (2006).

20. M. J. Song, D. S. Lee, J. H. Ahn, D. J. Kim, and S. C. Kim, J. Polym. Sci., Part A: Polym. Chem., 42, 772 (2004).

21. S. Y. Park, D. K. Han, and S. C. Kim, Macromolecules, 34, 8821 (2001).

22. S. Y. Park, B. R. Han, K. M. Na, D. K. Han, and S. C. Kim, Macromolecules, 36, 4115 (2003). 